\title{
DA UNIVERSIDADE AUTÔNOMA AO ENSINO SUPERIOR OPERACIONAL: CONSIDERAÇÕES SOBRE A CRISE DA UNIVERSIDADE E A CRISE DO ESTADO NACIONAL
}

\author{
Luís Antonio Groppo*
}

Recebido: jul. 2010

Aprovado: ago. 2010

*Professor do Programa de Mestrado em Educação do Unisal (Centro Universitário Salesiano de São Pau1o), Unidade Americana. Centro Universitário Adventista de São Paulo (Unasp), Engenheiro Coelho/SP. Pesquisador do CNPq. Doutor em Ciências Sociais e Mestre em Sociologia pela Unicamp (Universidade Estadual de Campinas). E-mail: luis.groppo@am.unisal.br

Resumo: Resgatando a relação entre o Estado nacional e a universidade moderna, comenta-se sobre a criação do mito-realidade da nação em consonância com o mito-realidade da universidade- instituição, a qual estaria destinada a pensar sua nação e sua época de modo autônomo. Após apresentar as crises da universidade - de hegemonia, de legitimidade e institucional - $\mathrm{o}$ artigo busca relacionar a mais séria destas crises, a institucional, que ameaça tornar a universidade-instituição autônoma em universidade operacional, com a crise daquele Estado nacional, no contexto da globalização do capital. Finda apresentando os principais contornos da crise institucional da universidade no Brasil contemporâneo.

Palavras-chave: Universidade. Autonomia universitária. Sistemas institucionais de ensino superior. Estado Nacional. Globalização. Universidade operacional.

\section{FROM THE AUTONOMOUS UNIVERSITY TO THE OPERATIONAL SUPERIOR EDUCATION: CONSIDERATIONS ON THE CRISIS OF THE UNIVERSITY AND THE CRISIS OF THE NATIONAL STATE}

Abstract: Rescuing the relation between the State-nation and the modern university, is commented on the creation of the myth-reality of the nation in accord with the myth-reality of the institution university, which would be destined to think its nation and its time in autonomous way. After to present the crises of the university - of hegemony, of legitimacy and institutional - the article searches to relate the most serious of these crises, the institutional one, that threat to become the university institution-autonomous in operational university, with the crisis of that State-nation, in the context of the globalization of the capital. It ends presenting the main contours of the institutional crisis of the university in Brazil contemporary.

Key words: University. University autonomy. Institutional systems of superior education. State-nation. Globalization. Operational university

\section{INTRODUÇÃO}

Levado a dissertar sobre o tema "Sociedades Nacionais e modelos institucionais de ensino superior", em um evento acadêmico, fiquei inicialmente incitado a fazer uma mera tipologia dos modelos de ensino superior. Contudo, notei que a primeira parte do tema - "sociedades nacionais" - poderia levar 
a outra discussão: a relação entre a formação, consolidação e crise (mas não desaparição) das sociedades nacionais modernas e a formação, consolidação e crise da universidade como instituição com autonomia relativa no seio destas sociedades. Resolvi fazer esta outra segunda discussão, com todos os riscos que isto implicava e que se demonstraram realmente muito sólidos. Contudo, veio à luz o esboço de um texto que considerei relevante apresentar ao restante da comunidade acadêmica, talvez menos severa em seu julgamento.

Neste sentido, pretendo abordar o processo em que aquela universidade-instituição hegemônica tende a se metamorfosear em uma universidade operacional, que contém em si e convive com diversas modalidades de ensino superior que não existiam antes ou eram secundárias. Esta discussão pode contribuir para a compreensão dos sentidos das reformas educacionais que vêm se abatendo sobre as instituições de ensino em nosso país há mais de uma década.

Dois são os objetivos principais deste artigo. O primeiro é promover algumas reflexões sobre a relação entre a chamada globalização do capitalismo e a crise - mas, de modo algum, desaparição - dos Estados, das nações e das universidades, os quais são atingidos por uma série de processos globais que transcendem as fronteiras das sociedades nacionais, que promovem homogeneizações e diferenciações. Criam-se desafios para a análise dos sistemas nacionais de ensino superior, desafios que precisam ser enfrentados, inclusive para fazer frente a tendências preocupantes de mercantilização do ensino superior e de sua subserviência ao produtivismo.

Como segundo objetivo, pretendo fazer considerações sobre alguns aspectos desta ascensão e crise da universidade no Brasil, destacando a atuação de alguns dos principais agentes neste processo, em especial o Estado.

Inicio o artigo considerando que a institucionalização da universidade significou o reconhecimento de sua autonomia relativa no seio das sociedades nacionais, ambas em processo de formação e consolidação ao longo da modernidade. Em seguida, apresento alguns modelos nacionais de Ensino Superior vigentes na segunda metade do século $\mathrm{XX}$, destacando não apenas a heterogeneidade relativa destes, mas o que elas indicam sobre o passado e o futuro da universidade moderna. Em terceiro lugar, discuto, com base em Boaventura de Sousa Santos, as crises da universidade, em especial a crise institucional, a mais recente e a mais preocupante destas crises. Após, abordo a crise institucional da universidade no Brasil, destacando os rumos da nação e do Estado em tempos de globalismo, assim como o papel do Estado como representante - ainda que contraditório e não exclusivamente - do capital e do poder global nas reformas educacionais. Enfim, faço algumas breves considerações conclusivas. 


\section{A HEGEMONIA DA UNIVERSIDADE}

Renato Ortiz em suas obras sobre a mundialização, em especial Um outro território (ORTIZ, 2000), registra a intrínseca relação entre Estado, nação e modernidade. Destaco primeiro, a relação entre nação, industrialismo e modernidade - pois, para Ortiz, a modernidade atinge sua plenitude apenas com a industrialização, em especial ao longo do século XIX. Segundo Ortiz, a sociedade industrial, gestada pelo processo de modernização, em destaque o século XIX, rompe com fronteiras sociais tradicionais. Primeiro, pela maior mobilidade resultante da divisão do trabalho mais complexa, que faz com que os indivíduos circulem ou precisem circular constantemente. Em segundo lugar, torna-se necessária uma cultura com maior grau de abrangência e integração, pois que é preciso "envolver o conjunto de membros dessa sociedade", o que é feito pela noção - a um tempo mito e realidade - de Nação. A nação "representa essa totalidade que transcende os indivíduos, os grupos e as classes sociais" (ORTIZ, 2000, p. 83). Conclui-se que "Nação e industrialismo são, portanto, fenômenos convergentes" e que "A nação se realiza historicamente através da modernidade" (p. 83).

A modernidade assistiu não apenas à emergência da nação e da cultura nacional como seu ambiente e sua "alma". Também foi responsável pela criação do Estado moderno, instituição que passa a monopolizar a coerção legítima nesta nova formação social, formação que transcende as localidades e as regionalidades. Esta instituição torna possível a ruptura com o funcionamento fragmentado do poder político, e, deste modo, prepara o terreno para a consolidação dos mercados capitalistas nacionais.

É claro que este processo, assim descrito, refere-se antes à Europa, em que tais fenômenos se conjugaram de modo mais pleno e ideal. Contudo, via imperialismo e modernização do mundo, estes modelos de nação, mercado, sociedade industrial e Estado, bem sabemos, seriam levados para todo o planeta, como parte mesmo do processo de internacionalização do capitalismo e da modernidade.

Outra instituição da modernidade ocidental viveria seus dias de glória e expansão planetária. É ela o tema principal deste texto. Trata-se da universidade moderna. Trindade (1999) descreve a contraditória jornada da universidade moderna, livrando-se das dependências típicas da universidade medieval para com a Igreja, o saber teológico e as tradições medievais. Universidade que vai ganhando forma com a proteção, a legislação e logo o controle das instituições estatais nascentes. Na Europa, o século XIX, após o período da invenção (final 
da Idade Média), da universidade renascentista e da universidade institucionalizadora da ciência (séculos XVII e XVIII), na Europa, vai constituir a universidade moderna, "introduzindo uma nova relação entre Estado e universidade" (ibid., p. 6).

Não se pode falar que um modelo único de universidade emergiu, mas antes de tendências mais ou menos gerais, as quais encaminham os sistemas de ensino superior para sua "nacionalização, estatização (França e Alemanha) e abolição do monopólio corporativo dos professores, iniciando-se o que se pode denominar 'papel social das universidades', com o desenvolvimento de três novas profissões de interesse dos governos: o engenheiro, o economista e o diplomata" (ibid., p. 10).

A França representará, mais que um exemplo de tardia superação da universidade medieval, o caso mais típico de sistema de ensino superior orientado pelo e para o Estado moderno - em especial após as reformas napoleônicas. Retomaremos este caso adiante.

A Alemanha e a Inglaterra, cada qual por diferentes motivos - a primeira, por conta de um Estado nacional apenas incipiente, a segunda por conta dos embates entre Parlamento e Coroa -, vão constituir um modelo de universidade em que esta estaria mais ligada à "nação" que ao Estado (ibid., p. 10-11). De todo modo, levando-se em conta a noção de "Estado ampliado" em Gramsci que seria formado tanto pela sociedade civil quanto pela sociedade política (o Estado em sentido estrito, como instituição que monopoliza o poder coativo legítimo $)^{1}$ - ainda aqui é nítida a relação íntima entre Estado-nação moderno e universidade moderna.

O século XIX é tempo de consolidação da sociedade industrial como sociedade nacional, sob a égide do Estado moderno e sob a inspiração da cultura nacional - mitos e realidades sempre contraditórias e em construção, nunca produtos bem-acabados de uma pretensa "natureza" do povo de cada país. Neste contexto, a instituição universidade se tornou o local privilegiado de produção de conhecimento e modelo de ensino superior. Mas, se foi hegemônica, a universidade nunca foi exclusiva como instituição de ensino superior, nem mesmo em seu auge nos séculos XIX e XX, tendo de dividir ao menos algum espaço com formas de ensino superior não-universitário, institutos de pesquisa não voltados ao ensino, institutos de pesquisa mantidos pelo Estado independentes da universidade, academias, escolas e faculdades isoladas etc.

1 Mesmo considerando que a sociedade civil - como conjunto de organizações de cunho privado, passíveis de orientação em prol da luta pela hegemonia (em vez da luta pelo poder coativo) - teria se desenvolvido mais claramente apenas no século XX, nos países da Europa Ocidental, segundo Gramsci. 
Mais recentemente, a universidade tem sofrido a concorrência, como lócus de reunião da intelligentsia, de entidades de pesquisa e pensamento ao estilo ONGs (Organizações Governamentais) (CARVALHO, 2007).

A universidade é uma criação histórica, estreitamente relacionada com os processos de modernização, os quais incluem a ascensão dos Estados modernos e das nações. Mas, como dito, se não foi exclusiva nos séculos XIX e XX, foi hegemônica:

As universidades sempre representaram apenas uma parte do que poderíamos denominar, de modo amplo, ensino superior. [...] Se aceitarmos atribuir à palavra universidade o sentido preciso de "comunidade (mais ou menos) autônoma de mestres e alunos reunidos para assegurar o ensino de um determinado número de disciplinas em um nível superior", parece claro que tal instituição é uma criação específica da civilização ocidental, nascida na Itália, França e na Inglaterra no início do século XIII. Este modelo, pelas vicissitudes múltiplas, perdurou até hoje [...] e disseminou-se mesmo por toda a Europa e, a partir do século XVI, sobretudo dos séculos XIX e XX, por todos os continentes. Ele tornou-se o elemento central dos sistemas de ensino superior e mesmo as instituições não-universitárias situam-se, em certa medida, em relação a ele, em situação de complementaridade ou de concorrência mais ou menos notória (CHARLES; VERGER apud MENDONÇA, 2000, p. 131).

Ao longo desta trajetória, em especial na sua sucursal alemã, a universidade moderna vai solidificar uma concepção sobre a sua suposta "natureza", "essência" ou dever-ser absoluto. Esta auto-mitificação constituiria - e em parte relevante, ainda constitui - o cerne do discurso da universidade-instituição autônoma. Uma boa expressão disto é feita por Karl Jaspers, em 1946, quando afirma a "missão eterna" da universidade:

A universidade é o lugar onde por concessão do Estado e da sociedade uma determinada época pode cultivar a mais lúcida consciência de si própria. Os seus membros congregam-se nela com o único objetivo de procurar, incondicionalmente, a verdade e apenas por amor à verdade. (apud SANTOS, 2001, p. 188).

Daí decorre, segundo Boaventura Sousa Santos (ibid.), que a investigação é o principal objetivo da universidade, que a universidade seria o centro da cultura (e não apenas da ciência) e que a universidade deveria ensinar a verdade buscada.

Desta idéia-mor vão se originar os diversos modelos institucionais de ensino superior, conforme peculiaridades das sociedades nacionais e suas trajetórias 
históricas. Hoje nos parece mais claro o caráter histórico, portanto, suscetível a mudanças e até superação, desta idéia mestra de universidade.

Antes disto, contudo, desde logo a universidade moderna sofreu - e sofre -diferentes formas de pressão e influência. A universidade foi expandindo suas funções tanto quanto expandindo-se em número e tipo de estabelecimentos. As diferentes reformas da universidade buscaram manter sob controle as contradições via gestão das tensões provocadas, por meio de mecanismos de dispersão (ibid.).

\section{ALGUNS MODELOS NACIONAIS DE ENSINO SUPERIOR}

Antes de discutir mais sobre tais tensões e reformas, gostaria de comentar, ainda que brevemente, sobre alguns dos mais marcantes modelos de universidade. $\mathrm{O}$ exemplo mais forte do que foi a universidade moderna ligada umbilicalmente ao Estado é a universidade na França. Segundo Darcy Ribeiro (1975), o modelo moderno de ensino superior francês é mais fruto da revolução industrial e das reformas napoleônicas, e menos que da universidade medieval de Paris.

As reformas napoleônicas buscaram institucionalizar o ensino superior considerando-o como serviço público, em função da unificação política e cultural das províncias. Este se erigiu sob valores de um novo humanismo baseado na ciência, na defesa dos direitos humanos e em prol da difusão de um novo saber tecnológico oriundo da revolução industrial. A institucionalização do ensino superior criou, entretanto, uma burocracia racional, seletiva e impessoal, conformando um modelo burocrático de ensino superior.

Ainda no século XIX, a Terceira República reorganizou as escolas e faculdades em federações de unidades independentes, as quais foram chamadas de "universidade". Contudo, não se superou o tradicional isolamento entre as entidades componentes desta federação e a dispersão destas. Enfim, o sistema de concursos para os altos quadros da universidade consolidou todo um sistema voltado mais aos exames que ao ensino (ibid.).

O segundo exemplo clássico de modelo de ensino superior que gostaria de destacar é o norte-americano. Na verdade, desejo menos apresentar os complexos e múltiplos modelos institucionais de ensino superior nos Estados Unidos, e mais discutir uma tendência, forte nas principais universidades norte-americanas na segunda metade do século XX. Tendência que demonstra que, se a universidade contemporânea está deixando de ser braço da institucionalização do Estado e enraizamento da nação, ela não está deixando de ser 
organismo a serviço do capital e de seus mercados. Também, que tal tendência de subsunção da universidade ao capital não é nova - e, provavelmente, nem mesmo uma aberração.

Uma forte característica da universidade nos Estados Unidos, em especial das universidades mais prestigiadas, foi sua vinculação orgânica, no contexto da Guerra Fria, ao "complexo militar-industrial-acadêmico" criado em prol do esforço de superar militarmente a União Soviética, com base na doutrina da superioridade tecnológica das armas (que seria o fator decisivo na vitória militar) (MEDEIROS, 2004).

Destaca-se a concepção do principal financiador e encomendante deste complexo, o Departamento de Defesa, para quem o único constrangimento para adotar armamento superior era a "viabilidade tecnológica" e não custos ou riscos, o que implicou em pesados investimentos e um encurtamento enorme do tempo entre as fases de inovação e aplicação (ibid.).

A militarização real ou virtual da universidade nos Estados Unidos, em tempos de Guerra Fria, levou Darcy Ribeiro (1975, p. 71) a redigir esta contundente denúncia:

Nesta universidade americana recrutada para a guerra, mais do que para o progresso do saber, o que se espera da matemática e da física são novas bombas, raios da morte e métodos de medir a eficácia dos armamentos. Da biologia e da química, são esperados germens de enfermidades e gases alucinantes; da sociologia, psicologia e antropologia, projetos de controle estratégico-preventivo de camadas sociais virtualmente revolucionárias, e sistemas de utilização dos meios de comunicação com o objetivo de doutrinação em massa.

Estes dois exemplos ajudam a entender o que a universidade do Terceiro Mundo, em especial da América Latina, tinha especialmente diante dos seus olhos, tendo em vista as pressões por sua reforma e adequação aos "novos tempos": uma universidade burocratizada, em dificuldades para dar conta das novas exigências sociais e econômicas (o modelo francês); uma universidade tecnificada, que já deixava de ser uma instituição relativamente autônoma e se tornava organismo de atendimento de necessidades mais ou menos urgentes do complexo industrial-militar (o modelo norte-americano). ${ }^{2}$

As universidades da América Latina constituíram-se, em geral, a partir do problemático modelo francês, no sentido de conformarem uma "estrutura federativa, profissionalizada, rígida, autárquica, estagnada, duplicadora, auto-

2 Faço esta discussão de modo mais detalhado em Groppo (2006). 
crática e plutocrática" (RIBEIRO, 1975, p. 11). A universidade latino-americana era extremamente rígida e elitista, apesar de o ativismo estudantil contra este modelo ter dado origem a um elemento que foi marcante nas universidades hispano-americanas no século XX: o co-governo estudantil.

Também houve esforços episódicos de reforma da universidade, mas que, em geral, criaram apenas somatórias à estrutura original, como meros apêndices confirmando a crítica de Santos (2001) sobre o modo de gestão das contradições da universidade. É claro, algumas tentativas foram mais sérias, mas fracassadas, como no Uruguai, Argentina, Colômbia, Chile, Peru e até no Brasil (como a criação da Faculdade de Filosofia, Letras e Ciências da Universidade de São Paulo - nos anos 1930 - e, depois, da Universidade de Brasília - praticamente desmontada no início do Regime Militar),

Ainda sobre o Brasil, gostaria de destacar apenas alguns aspectos do sistema de ensino superior brasileiro gestado por sua Reforma durante o Regime Militar, em especial no final dos anos 1960. Configurou-se o que Luiz Antonio Cunha (jan./abr. de 1999) chamou de universidade taylorista, produzida por uma reforma orientada, segundo Anísio Teixeira, pelo "âmbito da racionalidade administrativa e econômica" (apud MENDONÇA, 2000, p. 147).

Entre as medidas, para além das violentas intervenções nos campi universitário para conter agitação estudantil e para expurgar quadros docentes, tornou-se patente ao Regime que era preciso enfrentar a questão da imponderável institucionalização do ensino superior e a questão dos excedentes - a demanda pelo ensino superior. Decorrente das reformas legais e institucionais, houve um processo de consolidação das universidades públicas, com a institucionalização da carreira docente e a implantação definitiva da pós-graduação - o que desenvolveria a pesquisa e melhoraria a qualificação docente (MENDONÇA, ibid.).

Mas esta institucionalização deu-se à custa de uma não-efetivação da autonomia universitária, já que se impôs o controle centralizado pelo Estado dos recursos materiais e se constituiu o governo desta universidade por um "pacto" firmado entre oligarquias acadêmicas tradicionais e novos segmentos docentes. Também esta institucionalização, na busca de atender à demanda pelo ensino superior, resultou em uma maior heterogeneidade do sistema. $\mathrm{O}$ atendimento à demanda se fez, em especial, pelo estimulo à iniciativa privada, o que fez explodir ensino superior privado - em especial via multiplicação de unidades isoladas - gerando um sistema dual: universidades públicas versus unidades isoladas particulares, cuja distinção se dava mais pela qualidade do ensino (ibid.) 


\section{CRISES DA UNIVERSIDADE}

Aludimos acima para a dificuldade da universidade latino-americana adequar-se às transformações sócio-econômicas na segunda metade do século XX. Esta não foi uma dificuldade exclusiva desta parte do mundo. Também não foi a única crise enfrentada pela universidade. Enfim, não foi nem mesmo a sua crise mais sensível.

Com base no texto de Boaventura de Sousa Santos, (2001) "Da idéia de universidade à universidade das idéias", gostaria de apresentar as três grandes crises da universidade moderna: de hegemonia, de legitimidade e institucional. A crise da hegemonia vai se iniciar já no final do século XIX, pouco após esta universidade ter se consolidado, mas será mais visível na segunda metade do século $\mathrm{XX}$, no mesmo momento em que tem início a crise de legitimidade. A crise institucional é mais recente, ainda que com fortes sinais já nos anos 1970 e 80. Mas estas crises conviveram e convivem no tempo, já que, a rigor, nenhuma destas crises e suas contradições foram resolvidas - apenas, via reformas, estendidas no espaço e no tempo, ampliando as funções da universidade, seu número e diversidade, gerindo as tensões mais que as solvendo.

A crise de hegemonia significou a crise dos pressupostos que sustentavam o modelo de universidade consolidado no século XIX, os quais afirmavam ser esta o "lugar privilegiado da produção da alta cultura e conhecimento científico avançado" (SANTOS, 2001, p. 139). Primeiro, a visão da alta cultura ou cultura erudita como uma "cultura-sujeito" centrada na universidade vai enfrentar a ascensão da cultura de massa, que, ao seu modo, também era e é uma cultura-sujeito. A democratização da universidade foi uma frustrada tentativa de massificar a própria cultura erudita, mas esta acabou por gerar uma hierarquia entre universidades de elite e universidade de massa.

O segundo pressuposto era a separação entre educação superior e trabalho, concebidos como mundos incomunicáveis. Mas isto tem que mudar diante das transformações econômicas desde o final do século XIX. A solução tentada foi substituir a separação pela seqüência educação-trabalho, em que a educação se tornaria educação para o trabalho. Esta foi o modo como a universidade conseguiu manter sua centralidade e papel ativo nas mudanças tecnológicas ao longo do século XX.

O terceiro pressuposto firmava a separação entre teoria e prática, em que a universidade seria o lugar por excelência da produção do conhecimento científico. Derivava daí a primazia da ciência pura ou básica. Contudo, em especial nos anos 1960 e 70, foi forte a pressão para uso prático da ciência, 
resultando numa subsunção mais direta da universidade ao mercado e ao capital. A universidade vai mesmo perder o monopólio da pesquisa científica, com empresas multinacionais e mesmo o Estado criando seus próprios centros de pesquisa não-universitários. O próprio Estado passa a selecionar universidades de "excelência" em pesquisa para privilegiar recursos financeiros. Deste modo, reforçava-se a estratificação das universidades: algumas passam a ter concentração de recursos para pesquisa e outras para disseminar o conhecimento. Outros efeitos importantes foram: incentivo à procura de recursos externos, em especial em parcerias com indústrias; perturbação dos critérios de prioridade à pesquisa; crescente força de outro modelo de pesquisador - que Robert Merton identifica nos laboratórios de pesquisa das grandes indústrias - não necessariamente comprometido com a noção de livre discussão de resultados, e que acaba sendo visto como o modelo ideal de pesquisador mesmo nas universidades públicas (ALMEIDA, 2003); o alargamento dos papéis aceitos pelo docente, incluindo a consultoria de empresas e formação e gestão de empresas - as próprias universidades passam a criar empresas juniores e incubadoras de empresas.

A segunda crise é a de legitimidade, que advém da pressão pela democratização da universidade, para que ela não fosse uma instituição reservada apenas às elites e tão somente com a função de formar elites. Tal pressão veio de movimentos sociais e aspirações sociais das classes médias e mesmo populares, bem como do contexto das políticas sociais redistributivas do Estado Providência. Adota-se, segundo Boaventura de Sousa Santos, uma solução de compromisso, a saber, a desvinculação da procura da universidade da procura da democracia através da estratificação e diferenciação interna da universidade. Donde provêm dualismos, como ensino superior universitário e não-universitário, universidade de elite e de massas, cursos de grande prestígio e desvalorizados etc.

Enfim, a crise mais recente e mais visível nos últimos anos: a crise institucional da universidade, que é, basicamente, a crise da autonomia (relativa) da universidade. Está em causa agora talvez o pilar da universidade moderna: a autonomia universitária. Esta se expressa, primeiro, pela crise de financiamento. A contração do orçamento social no contexto da crise do Estado providência e das políticas redistributivas atinge em cheio a Universidade pública, que passa por cortes orçamentais significativos.

Outra expressão é a imposição da avaliação externa, em que a produtividade passa a ser o critério principal de avaliação, algo que até então era mais ou menos estranho à universidade. Mesmo que a avaliação seja exercida pela própria universidade, ainda assim ela será externa pois se guia por valores e exigências externos à universidade. Ao mesmo tempo, se o Estado tem se 
tornado menos presente como financiador, entretanto, ele tem se tornado mais presente na vigilância e na intromissão em relação à aplicação e gestão deste parco financiamento.

Como terceira expressão, já presente acima, está o produtivismo. Na busca de atender os novos critérios e na busca de formas alternativas de financiamento, a universidade vai tendo de participar cada vez mais ativamente na luta pela produção industrial.

Complementando estas idéias sobre a crise institucional da universidade, gostaria de citar algumas observações feitas por José Dias Sobrinho (2005), que destaca os efeitos sobre o ensino superior das novas demandas do "pensamento dominante", oriundas dos avanços em ciência e tecnologia e dos processos de globalização: "foco mais centrado na função econômica e nas capacidades laborais" (p. 167); demandas principais com "sentido muito mais imediatista, pragmático e individualista" (ibid.); orientação para o mercado, não para o saber como bem público; adoção acrítica da tese da sociedade do conhecimento - em um contexto em que a competitividade tem no conhecimento e na capacidade de aprender bases muito importantes, gera-se uma crença até determinista "no conhecimento como insumo econômico de grande importância estratégica para a competitividade" (ibid.); a pesquisa nas instituições universitárias se torna refém da inovação tecnológica e certos tipos de conhecimento passam a ter muito mais valor (são aqueles "relacionados com os processos de inovação tecnológica e produção industrial" [ibid. p. 168]); criação de políticas e instâncias de controle sobre a finalização da ciência, determinando os temas, a epistemologia e metodologias adotadas, com base na avaliação e nas políticas de financiamento; e diferenciação dos sistemas universitários, entre nações e dentro das nações, neste novo concerto da globalização do capitalismo - se para todos se exige mais e melhor escolarização, não se exige de todos a oferta da mais qualificada forma de educação no jogo da globalização, já que, para boa parte dos países, o sistema de ensino deve ser simples provedora de mãode-obra barata.

Pesquisa de P. Shugurensky e J. Naidorf (2004) indicam ainda outro aspecto bastante desalentador, oriundo da crise institucional da universidade: a metamorfose da cultura acadêmica. Segundo estes pesquisadores, houve profundas mudanças, em especial ao longo dos anos 1980, na cultura acadêmica dos docentes universitários do Canadá e Argentina (os casos estudados por eles), sob o impacto dos processos acima descritos, em especial das políticas neoliberais de "mercadorização do conhecimento". Destes processos resultou um verdadeiro capitalismo acadêmico. 
Se a cultura acadêmica nas universidades públicas de Argentina e Canadá era "quase indiferente quer contra o estabelecimento de vínculos mais estreitos com as empresas" (p. 1000), a partir do final do século XX passa a considerar tais vínculos como "uma realidade inevitável e muitas vezes até desejável" ( $\mathrm{p}$. 1000). Esta mudança, que podemos observar, com suas especificidades, em nosso país também, se deu muito rapidamente e quase sem debates fora ou dentro da universidade.

Segundo Marilena Chauí (2003), com base em conceitos de Michel Freitag, a reforma do ensino superior realizada no Brasil pelo governo Fernando Henrique Cardoso (1995-2002) é um forte exemplo desta outra coisa em que está se metamorfoseando não apenas a cultura acadêmica, mas sim toda a universidade .

Chauí (ibid.) considera que a crise institucional encaminha a universidade para deixar de ser efetivamente uma instituição, metamorfoseando-se em uma organização. Da universidade instituição quase-autônoma, estaríamos passando à era da universidade operacional. Segundo ela, a universidade passa a se definir como uma organização social, não mais como uma instituição social. Se a instituição "aspira à universalidade", tendo "a sociedade como seu principio e referência normativa e valorativa", a organização é uma "prática social determinada de acordo com sua funcionalidade [...], referida ao conjunto de meios (administrativos) particulares para obtenção de um objetivo particular" (CHAUÍ, ibid., p. 6).

A universidade-organização, ou universidade operacional é uma organização prestadora de serviços e em competição com outras universidades operacionais. Tem de refazer-se constantemente em prol das demandas da economia flexibilizada e flexibilizadora: "A permanência de uma organização depende muito pouco de sua estrutura interna e muito mais de sua capacidade de adaptar-se celeramente a mudanças rápidas da superfície do 'meio ambiente'. Donde o interesse pela idéia de flexibilidade, que indica a capacidade adaptativa a mudanças contínuas e inesperadas" (ibid., p. 7). ${ }^{3}$

Assim, a ascensão da universidade operacional tem íntima relação com os processos que implicam a transformação do capitalismo e a própria crise do Estado nacional moderno, no contexto da flexibilização do trabalho, da acumulação flexível do capital, da emergência de uma suposta "sociedade do conhecimento" e da globalização.

Compreender alguns aspectos da mudança do capitalismo que, da base territorial nacional, passa a operar em base internacional, transnacional e, enfim,

3 Propostas de especialistas em economia da educação e gestão do ensino da Universidade de Pensilvânia, Estados Unidos, ligados à revista Policy Perspective, não deixaram por menos, e desenharam um modelo de universidade com base na lógica de que ela deve "responder a diversas necessidades que lhe são externas" e se tornar uma "organização multifuncional, indispensável e utilitária" (apud TRINDADE, 1999, p. 13). 
global, pode nos ajudar a traçar algumas das perspectivas presentes e futuras relativas a esta universidade em crise institucional, mais especificamente no caso brasileiro. É isto que procuro fazer no final deste item, já nos preparando para o item a seguir.

Segundo Renato Ortiz (2000), a globalização implica em: a) quebra de fronteiras e mobilidade interplanetária, graças à revolução tecnológica (comunicação, transporte, produção e trabalho); b) desterritorialização (diluição dos limites) das culturas - processo que ocorre desde o início da modernidade, mas que hoje atinge o mundo todo, quando temos a radicalização do desenraizamento, de maneira a fazer com que o meio a nossa volta fique cheio de objetos de uma civilização desterritorializada ("luz elétrica, ônibus, automóveis, aviões, televisores, computadores, supermercados, cinemas, shopping centers, ruas, avenidas e aeroportos [...]" [ibid. p. 40]); c) reterritorialização dos objetos da modernidade-mundo, ou seja, o enraizamento da cultura moderna nos nossos hábitos cotidianos, a penetração da modernidade-mundo no nosso cotidiano.

Deste modo, as contradições do processo de modernização das sociedades passam não mais a ser contidas no interior das fronteiras do Estado-nação. A modernização vai agora exigir um desenraizamento ainda mais profundo de indivíduos e grupos, para além da subsunção de localismos e regionalismos pelo nacionalismo:

[...] a relação entre nação e modernidade se rompeu. Historicamente, a nação realizou-se através da modernidade, e vice-versa. No entanto, desde o seu início, aquela continha um movimento próprio, uma tendência que dificilmente se confinaria aos limites da realidade nacional. Com o avançar da História, a modernidade torna-se mundial. Ela é hoje modernidade-mundo (ibid., p. 144).

Com a globalização, perdeu o Estado-nação o "monopólio em conferir sentido às ações coletivas", de dar norte à "política", tendo de competir com outras instâncias infra-nacionais e supra-nacionais. Inclusive, não é mais fácil falar em "projeto nacional" como outrora (ibid., p. 129). Se nação e cultura nacional perdem centralidade - mas, jamais, a validade - do mesmo modo o Estado nacional se torna elemento do jogo das forças da globalização. Octavio Ianni (2000) vai ainda mais longe, afirmando taxativamente que, no Brasil, como em praticamente todo o mundo, o Estado tornou-se instrumento e a nação "província" do capitalismo global. 


\section{A CRISE INSTITUCIONAL NO ENSINO SUPERIOR BRASILEIRO}

$\mathrm{Na}$ crise institucional da universidade brasileira, vemos que esta se dá em meio a outras crises pretéritas ainda em aberto - a crise da hegemonia, em uma universidade que se institucionalizou sob a lógica de um Estado autoritário, durante o Regime Militar, e a crise da legitimidade, com a questão ainda a resolver relativa ao acesso das camadas médias e populares a um ensino superior de qualidade. Inclusive dizendo responder a estas outras crises, foi no Brasil o Estado, paradoxalmente, o demiurgo das reformas que iriam supostamente resolver as contradições de um sistema de ensino superior mal entrado na modernidade e empurrado desde logo para a "pós-modernidade" global. A crise do Estado nacional - que deixa de ser o território-mor da sociedade modernizada - se "resolve" pela intervenção do próprio Estado, agora tornado agente - ainda que contraditório e contradito - das forças transnacionais que nos empurram para a economia e a sociedade globais. E a universidade, como não poderia deixar de ser, que teve no Brasil uma acidentada trajetória que lhe prometeu a institucionalização mas só a cedeu num contexto autoritário de pequena autonomia, é levada expressamente a se operacionalizar num contexto mais sutil do autoritarismo da globalização neoliberal.

No Brasil, a política educacional de meados dos anos 1990 aos dias atuais modificou grande parte do "arcabouço jurídico-institucional da educação brasileira”, o que afetou enormemente o ensino superior (BRANDÃO, 2005).

O ano de 1994 marca a chegada de um novo grupo político ao poder, com maciço apoio parlamentar, com certo projeto definido de política educacional pautado em especial pelas diretrizes definidas pelo Banco Mundial. Entre as diretrizes do Banco Mundial para a educação nos países ditos "em desenvolvimento", destacam-se:

[...] maior diferenciação das instituições, enorme incentivo àquelas privadas de ensino superior, diversificação das fontes de financiamento, ênfase produtivista, distribuição dos poucos recursos estatais sob o critério de desempenho e priorização da educação fundamental e secundária pública em detrimento da educação superior pública (BRANDÃO, 2005, p. 78).

Com suas medidas, paulatinamente este governo vai reformando a educação, incluindo o ensino superior. Vejamos, com base em Brandão (2005). Primeiro, a Lei n. 9.131/95, que criou o Conselho Nacional de Educação e o Exame Nacional de Cursos (o "Provão"). Segundo, a lei 
n. 9.1192/95, que modificou o processo de escolha dos dirigentes universitários e que depois seria incorporada à Lei de Diretrizes e Bases da Educação: a nova lei para escolha dos dirigentes personificou as escolhas ao adotar o sistema de votação uninominal e afrontou o princípio da paridade ao dar o peso de $70 \%$ para o segmento docente.

Terceiro, a lei de Diretrizes e Bases da Educação Nacional (LDB), n 9.394/96, cujo projeto aprovado não foi o debatido e criado com grande participação da sociedade civil e política desde os anos 1980, mas sim aquele criado no interior do governo Fernando Henrique Cardoso. A forma com que foi imposta a LDB ilustra o modo como o Estado em tempos de globalização impõe suas reformas, numa nova e sutil condição autoritária. No que se refere ao Ensino Superior, a LDB criou cursos seqüenciais por campo de saber (mas cujo diploma não equivale ao de graduação), reduziu a exigência de qualificação do corpo docente e em regime de dedicação integral em relação ao projeto original da LDB (1/3 em vez de metade), e manteve ainda indefinida a regulamentação da autonomia universitária das universidades federais, em especial sobre o financiamento federal.

Quarto, a lei n, 10.172/01 aprovou o Plano Nacional de Educação (PNE): assim como se deu com LDB, projeto debatido na sociedade civil foi substituído por outro elaborado pelo governo FHC; entre as 35 metas para o ensino superior, houve o veto presidencial justo das metas que elevavam o gasto público total em educação e que ampliavam a oferta de ensino superior público - o que vem contribuindo para que as outras metas, em geral positivas, não possam ser cumpridas.

Entre os processos permitidos por ou apesar destas leis, tivemos o crescimento, de 1995 a 2002, de 160\% do número de cursos superiores privados (de 3.500 para 9.100), enquanto que os cursos públicos aumentaram 86\% (2.800 para 5.200). Dados indicam diminuição de 57,8\% dos investimentos do Ministério da Educação (MEC) entre 1995 e 2003 (ibid.).

Estas transformações normativas e institucionais levam o sistema de ensino superior brasileiro a seguir tendências de outros países no que se refere à vinculação avaliação-financiamento, como modo de "forçar as instituições de ensino superior a alterar o seu modo de gestão e de produção acadêmica e lançar-se no que se passou a chamar de quase-mercado educacional" (AMARAL, 2005). No Brasil, estas reformas e esta vinculação têm gerado um híbrido público-privado nas instituições públicas, via privatização dissimulada em vez de direta, nos 
quais os poucos recursos obrigam instituições a buscar fontes alternativas que passam a ser mesmo, muitas vezes, a razão de ser destas, como prestação de serviços, assessorias, consultorias, cursos de especialização e extensão e até cobrança de taxas.

Algumas ações neste sentido se vêem no modelo que acabou sendo adotado para a distribuição de recursos entre Instituições Federais de Ensino Superior (cujo efeito foi aumentar a segregação entre instituições fortes, que passam a ter mais recursos ainda, e débeis), o estabelecimento da Gratificação de Estímulo à Docência como complemento ao salário docente por "produtividade" (gerando "aulismo" e busca desenfreada de eventos para fazer pontos) e o "Provão" (ibid.).

A chegada de Lula e do Partido dos Trabalhadores ao governo federal parecia significar o rompimento para com esta política. Houve mudanças, mas parece que a linha principal das mudanças não foi nem rompido nem interrompido. Como exemplos, o Programa Universidade para Todos (ProUni), tornado lei em 2005, o qual vem sendo criticado por ter, segundo alguns, como principal função a transferência recursos públicos para entidades privadas em crise - em vez de expandir a rede pública de educação. Outra medida foi a substituição do Provão pelo SINAES (Sistema Nacional de Avaliação do Ensino Superior), mas sem discussão maior sobre a necessidade destas grandes avaliações nacionais (ibid.).

Enfim, temos o Projeto do governo Lula para a Reforma do Ensino Superior. Ele foi encaminhado ao Congresso Nacional em julho de 2006. Lendo o Projeto, vêem-se muitos pontos com os quais se pode e deve concordar. Mas há um aspecto que chamou a atenção, negativamente, de José Rodrigues (2007): o Projeto considera a educação superior antes como "bem público" do que como direito. Isto é interpretado por ele como uma solução de compromisso, tentando compor os diferentes setores sociais interessados na Reforma, em especial frações da burguesia produtiva e de serviços educacionais.

Para Rodrigues (ibid.), adota-se o pressuposto de que a educação superior deve contribuir para integrar a economia nacional à economia mundial, associando de modo linear educação e desenvolvimento econômico. Enfim, incentiva-se uma fragmentação ainda maior do sistema de educação superior, ao permitir novas instituições de ensino superior público como centros universitários, universidades especializadas por campo de saber e instituições consorciadas.

A posição do empresariado produtivo em relação à reforma educacional, exposta em documentos do CNI (Confederação Nacional da Indústria), manifestase a favor da preservação das instituições públicas, inclusive gratuitas. Isto é bem compreensível, já que são as únicas com qualidade para o desafio maior e 
mais importante - segundo o CNI - de servir à inovação e ao desenvolvimento científico e tecnológico. Contudo, o empresariado conclama por mudanças na natureza destas instituições, reformando o conceito de autonomia universitária, atrelando-a à avaliação externa segundo parâmetros produtivos. Por sua vez, a posição do empresariado de serviços educacionais deriva da sua concepção da educação como bem mercantil e da sua defesa da livre iniciativa no "mercado de bens educacionais". Ambos os setores criticam o Projeto pela sua suposta insuficiência nestes pontos.

Apesar de tudo, Rodrigues (ibid.) considera que a Reforma oferece uma solução, uma conciliação possível, menos nos objetivos explícitos e mais nos implícitos. Tal solução atende mais ao empresariado industrial, mas a proposta de considerar a educação superior com bem público, portanto, mercadoria especial sob controle mais estrito do Estado, não é totalmente divergente dos interesses do empresariado de serviços.

\section{CONCLUSÃO}

Alguns aspectos e processos desta constelação mais ampla de transformações sócio-históricas, que muitos chamam de globalização, devem ser considerados para pensar os contornos assumidos na relação entre sistema de ensino superior e sociedade nacional: as forças privatizadoras do capital em sua fase flexibilizadora, neoliberal e orientada pelas tecnologias informacionais; as orientações das agências supranacionais, inclusive financeiras, como o Banco Mundial; e o novo papel do Estado como regulador e avaliador, mais do que finaciador, do ensino superior.

Uma proposta de Renato Ortiz em Um outro território pode contribuir para a compreensão e mesmo para o posicionamento diante destes desafios. Ele propõe um olhar analítico sob ponto de vista desterritorializado, liberto "dos constrangimentos locais e nacionais" (2000, p. 21). Diz que é preciso pensar primeiro o mundo "no seu fluxo", para depois pensar nossas realidades nacionais e locais, e que as nações agora são "parte intrínseca da totalidade mundo". (p. 26). Como citado, Octavio Ianni (2000) foi ainda mais longe, afirmando em várias ocasiões que a nação se torna província do capitalismo mundial.

Pensando deste modo "desterritorializado", percebe-se que estes processos que vêm influindo na transformação dos sistemas de ensino superior, inclusive no Brasil, não têm origem apenas na dinâmica nacional, assim como as "soluções" propostas e implementadas de reforma não são apenas sugeridas ou impostas por agentes políticos da nação. 
Como última consideração, vemos que alguns resultados destes complexos processos parecem se destacar, entre os quais a diversificação do Ensino Superior, sua expansão degradada e a perda da centralidade da concepção clássica de universidade na configuração deste sistema, implicando, entre outros, na decadência da noção tradicional de autonomia da universidade.

\section{REFERÊNCIAS}

ALMEIDA, Maria de Lourdes Pinto de. A academia e o problema do público e do privado: aspectos históricos da relação da universidade com a empresa. Ciências da Educação, Aparecida, v. 5, n. 9, p. 217-233, $2^{\circ}$ semestre, 2003.

AMARAL, Nelson Cardoso. A vinculação avaliação/financiamento na educação superior brasileira. Impulso, Piracicaba, v. 16, n. 40, p. 81-91, 2005.

BRANDÃO, C. F. Política educacional para a educação superior brasileira na última década. Impulso, Piracicaba, v. 16, n. 40, p. 69-80, 2005.

CARVALHO, Maria Alice Rezende de. Temas sobre a organização dos intelectuais no Brasil. Revista Brasileira de Ciências Sociais, São Paulo, v. 22, n. 66, p. 17-32, out. 2007.

CHAUÍ, Marilena. A universidade pública sob nova perspectiva. Revista Brasileira de Educação, Campinas, n. 24, p. 5-15, set./dez. 2003.

CUNHA, Luiz Antonio. A universidade brasileira. Entre o taylorismo e a anarquia. Revista Brasileira de Educação, Campinas, n. 10, p. 90-96, jan./ abr. 1999.

DIAS SOBRINHO, José. Educação superior, globalização e democratização. Qual universidade. Revista Brasileira de Educação, Campinas, n. 28, p. 164-172, jan./abr. 2005.

IANNI, Octavio. Enigmas da modernidade mundo. Rio de Janeiro: Civilização Brasileira, 2000.

MEDEIROS, Carlos Aguiar de. O desenvolvimento tecnológico americano no pós-guerra como um empreendimento militar. In: FIORI, J. L. (Org.). O poder americano. Petrópolis: Vozes, 2004. p. 225-252. 
MENDONÇA, Ana Waleska Pollo Campos. A universidade no Brasil. Revista Brasileira de Educação, Campinas, n. 14, p. 131-150, maio/ago. 2000 .

GROPPO, Luís Antonio. Autogestão, universidade e movimento estudantil. Campinas: Autores Associados, 2006.

ORTIZ, Renato. Um outro território. Ensaios sobre a mundialização. 2 ed. Rev. e ampl. São Paulo: Olho Dágua, 2000.

RIBEIRO, Darcy A universidade necessária. 2. ed. Rio de Janeiro: Paz e Terra, 1975.

RODRIGUES, J. Frações burguesas em disputa e a educação superior no governo Lula. Revista Brasileira de Educação, Campinas, v. 12, n. 34, p. 120-136, jan./abr. 2007.

SANTOS, Boaventura de Sousa. Da idéia de universidade à universidade de idéias. In: . Pela mão de Alice: o social e o político na pósmodernidade. São Paulo: Corteza, 2001, p. 187-233.

SHUGURENSKY, P.; NAIDORF, J. Parceria universidade-empresa e mudanças na cultura acadêmica: análise comparativa dos casos da Argentina e do Canadá. Educação \& Sociedade, Campinas, v. 25, n. 88, p. 997-1022, out. 2004.

TRINDADE, Hélgio. Universidade em perspectiva. Sociedade, conhecimento e poder. Revista Brasileira de Educação, Campinas, n. 10, p. 5-15, jan./abr. 1999. 